\title{
Analysis of rumen microbial populations in lactating dairy cattle fed diets varying in carbohydrate profiles and Saccharomyces cerevisiae fermentation product
}

\author{
C. R. Mullins,${ }^{* 1}$ L. K. Mamedova, ${ }^{*}$ A. J. Carpenter, ${ }^{*}$ Y. Ying, $\dagger^{2}$ M. S. Allen, $\dagger$ I. Yoon, $\ddagger$ and B. J. Bradford ${ }^{* 3}$ \\ *Department of Animal Sciences and Industry, Kansas State University, Manhattan 66506 \\ †Department of Animal Science, Michigan State University, East Lansing 48824 \\ ‡Diamond V, Cedar Rapids, IA 52404
}

\begin{abstract}
The rumen microbial ecosystem is a critical factor that links diets to bovine physiology and productivity; however, information about dietary effects on microbial populations has generally been limited to small numbers of samples and qualitative assessment. To assess whether consistent shifts in microbial populations occur in response to common dietary manipulations in dairy cattle, samples of rumen contents were collected from 2 studies for analysis by quantitative real-time PCR (qPCR). In one study, lactating Holstein cows (n $=8$ ) were fed diets in which a nonforage fiber source replaced an increasing proportion of forages and concentrates in a $4 \times 4$ Latin square design, and samples of ruminal digesta were collected at 9-h intervals over $3 \mathrm{~d}$ at the end of each period. In the second study, lactating Holstein cows $(\mathrm{n}=15)$ were fed diets with or without the inclusion of a Saccharomyces cerevisiae fermentation product (SCFP) in a crossover design. In this study, rumen liquid and solid samples were collected during total rumen evacuations before and after feeding in a 42 -h period. In total, 146 samples of ruminal digesta were used for microbial DNA isolation and analysis by qPCR. Validated primer sets were used to quantify total bacterial and anaerobic fungal populations as well as 12 well-studied bacterial taxa. The relative abundance of the target populations was similar to those previously reported. No significant treatment effects were observed for any target population. A significant interaction of treatment and dry matter intake was observed, however, for the abundance of Eubacterium ruminantium. Increasing dry matter intake was associated with a quadratic decrease in E. ruminantium populations in control animals but with a quadratic
\end{abstract}

\footnotetext{
Received March 7, 2013.

Accepted May 25, 2013.

${ }^{1}$ Current address: GPS Dairy Consulting, Maryville, MO 64468.

${ }^{2}$ Current address: Pennsylvania State University, University Park,

${ }^{3}$ Corresponding author: bbradfor@ksu.edu
} PA 16802. increase in E.ruminantium populations in cows fed SCFP. Analysis of sample time effects revealed that Fibrobacter succinogenes and fungal populations were more abundant postfeeding, whereas Ruminococcus albus tended to be more abundant prefeeding. Seven of the target taxa were more abundant in either the liquid or solid fractions of ruminal digesta. By accounting for the total mass of liquid and solid fractions in the rumen and the relative abundance of total bacteria in each fraction, it was estimated that $92 \%$ of total bacteria were found in the solid digesta fraction.

Key words: rumen, quantitative real-time PCR, microbial DNA

\section{INTRODUCTION}

Despite an improved fundamental understanding of the ruminal ecosystem in the latter half of the 20th century, relatively little research has been conducted to understand how common dietary changes influence the composition of this community in vivo. It is a widely held view in ruminant nutrition that rumen microbial populations adapt to dietary changes, and some evidence supports this view (Khafipour et al., 2009; Ramirez et al., 2012). However, some studies have shown that the rumen microbiome of an individual animal is remarkably resistant to change (Weimer et al., 2010a; Mohammed et al., 2012). It is possible, but unclear, that consideration of dietary influences on populations of ruminal microbes could improve the nutritional management of ruminants.

A longstanding challenge in the field of rumen microbiology has been the fact that many species inhabiting the rumen are difficult, if not impossible, to culture. The morphological and physiological similarities among related species present an additional challenge (Weimer et al., 1999). Traditional culture-based enumeration strategies therefore fail to reflect the true diversity and distribution of microbial species in the rumen. The advent of DNA-based detection techniques has provided the opportunity to accurately quantify taxa within a 
rumen microbial community in a culture-independent manner. A variety of DNA-based techniques are used by rumen microbiologists, each with advantages and disadvantages. Bias that could be introduced by inconsistent DNA extraction must be considered for all such techniques, although methods refined for ruminal samples appear to help avoid this problem ( $\mathrm{Yu}$ and Morrison, 2004). Techniques such as terminal restriction fragment length polymorphism analysis offer low-cost approaches to assess global shifts in bacterial populations (Belanche et al., 2012), but do not provide insight into which specific species are altered. Quantitative real-time PCR (qPCR), on the other hand, can provide information about the relative abundance of specific microbial taxa, but is dependent on adequate characterization of the population to allow for specific and exclusive primer pairs to be designed (Tajima et al., 2001). A third approach is to rely on DNA sequencing of either clone libraries or the entire ruminal metagenome. These techniques provide both a broad view of species in the rumen (including those not characterized) and the ability to identify and quantify specific populations.

Practical problems continue to prevent the widespread use of DNA sequencing approaches for analysis of the ruminal ecosystem, however. The cost of this technology is dropping rapidly, but still greatly exceeds the cost of $\mathrm{qPCR}$ analysis of individual populations. The high cost of sequencing approaches has generally resulted in sample sizes of 4 animals or fewer in published studies (Kong et al., 2010; Stiverson et al., 2011; Ramirez et al., 2012). Not surprisingly, these studies have often used relatively extreme dietary manipulations to cause changes large enough to be detectable with small samples sizes (Stiverson et al., 2011; Li et al., 2012). As a result, questions about the microbial population responses to dietary manipulations relevant to the dairy industry remain largely unanswered. The lower cost of $\mathrm{qPCR}$, in contrast, makes larger studies more feasible, potentially providing the power to detect subtle changes in the ruminal ecosystem.

The objective of this study was to quantify populations of 12 well-characterized ruminal taxa in response to dietary treatments from 2 experiments with lactating dairy cattle, to determine if observed treatment responses could be attributable to effects on these populations. Although these taxa represent a minority of the microbes in the rumen, they were used as sentinel populations, with the assumption that large, consistent shifts in rumen microbial ecology in response to diets would significantly alter the relative abundance of at least one of the 12 populations quantified. Focusing on well-studied populations should allow more inferences to be made about the metabolic consequences of changes in ruminal ecology, compared with assessment of the many species in the rumen that remain entirely uncharacterized.

\section{MATERIALS AND METHODS}

\section{Experiment 1}

Experimental procedures were approved by the Institutional Animal Care and Use Committee at Kansas State University (Manhattan). A detailed description of the design and procedures for this experiment has been published (Mullins et al., 2010). Briefly, this experiment was a replicated $4 \times 4$ Latin square design using 8 mid-lactation Holstein cows with ruminal cannulas to evaluate responses to diets that incorporated $0,11,23$, or $34 \%$ wet corn gluten feed (WCGF). Wet corn gluten feed replaced portions of dietary alfalfa, corn silage, corn grain, and soybean meal, but all diets had similar concentrations of NDF (29\%), NFC (39\%), CP (19\%), and ether extract (3.5\%). Cows were fed twice daily and milked 3 times daily throughout the experiment, and treatment periods were $28 \mathrm{~d}$.

Rumen samples were collected every $9 \mathrm{~h}$ from $\mathrm{d}$ 26 through 28 such that 8 samples were taken from each cow each period, representing every $3 \mathrm{~h}$ of a 24 -h period, thus accounting for diurnal variation. Grab samples of ruminal digesta were collected from 5 locations throughout the dorsal and ventral regions of the rumen. These samples were mixed, and a representative subsample $(200 \mathrm{~g})$ was collected and frozen at $-20^{\circ} \mathrm{C}$. Concerns about cows accessing feed from neighboring stalls led to the removal of data from 2 cows over 2 periods, resulting in a total of $6,7,7$, and 8 samples representing 0, 11, 23, and 34\% WCGF treatments, respectively (Mullins et al., 2010).

Before processing, frozen samples were thawed at room temperature until they became pliant, and then composited by cow and period. To prevent postsampling fermentation, an effort was made to minimize the amount of time samples remained at room temperature. Each composited sample was diluted (1:1) with distilled, deionized water and homogenized using a highspeed blender (Waring Commercial, Torrington, CT). A subsample was then obtained from the homogenized mixture and used for microbial DNA isolation by using a commercial kit (ZR Fecal DNA Kit, Zymo Research Corp., Orange, CA). This kit utilized bead-based processing to dissociate microbes from feed particles, followed by chemical- and filter-based isolation of total DNA. Bead-dissociation of bacteria from particles followed by column purification was validated by $\mathrm{Yu}$ and Morrison (2004) and shown to generate high-quality DNA compared with other popular methods. Isolated DNA was quantified by spectroscopy (Nanodrop-1000, 
Nanodrop Technologies Inc., Wilmington, DE), and sample volumes were adjusted to achieve uniform DNA concentrations across all samples.

Quantitative real-time PCR was used to determine the relative abundance of 9 bacterial populations using previously validated primers specific for genes encoding 16S ribosomal RNA (Denman and McSweeney, 2006; Stevenson and Weimer, 2007). Populations of anaerobic fungi were determined using a primer designed for regions of $18 \mathrm{~S}$ ribosomal RNA and internal transcribed spacer regions (Denman and McSweeney, 2006). Forward and reverse primer sequences are listed in Table 1. Each primer was included at a concentration of 200 $\mathrm{n} M$, except primers for Megasphaera elsdenii and the Selenomonas ruminantium group, which were included at $450 \mathrm{n} M$ concentrations. Quantitative real-time PCR was performed in triplicate for each sample using a commercial mix from a single DNA isolate for each sample (Power SYBR Green PCR Master Mix; Applied Biosystems, Foster City, CA). Each well included $4 \mu \mathrm{L}$ of DNA template in a $20-\mu \mathrm{L}$ volume. Fluorescence was monitored in real time using the Applied Biosystems Prism Fast 7500 sequence detection system (Applied Biosystems) with ROX used as a reference dye. For all primers, amplification consisted of an initial hold for $20 \mathrm{~s}$ followed by 40 cycles of $95^{\circ} \mathrm{C}$ for $3 \mathrm{~s}$ and $60^{\circ} \mathrm{C}$ for $30 \mathrm{~s}$. A normalized reporter value of 0.2 was used as the common threshold for all taxa. The number of cycles required to reach this threshold $\left(\mathbf{C}_{\mathbf{T}}\right)$ were recorded for each sample. The $\mathrm{C}_{\mathrm{T}}$ obtained for each total bacteria sample was used as the reference value for the other taxa-specific assays. Reaction efficiencies were estimated using a 4-point sample dilution curve on each plate. The slope derived from regressing $\mathrm{C}_{\mathrm{T}}$ values against their log-transformed dilution coefficients was used to calculate efficiency according to the equation $\mathrm{E}$ $=-1+10^{(-1 / \text { slope })}$. Because estimated efficiencies were relatively uniform across taxa (Table 1), the relative abundance of each population was calculated $\left(2^{-\Delta \mathrm{CT}}\right)$ without attempting to adjust for differences in efficiency. Specificity of amplification was assessed by melt curve analysis, and no evidence of off-target amplification was observed.

\section{Experiment 2}

Experimental procedures were approved by the Institutional Animal Care and Use Committee at Michigan State University (East Lansing). The design and methods used in this experiment have been reported previously (Allen and Ying, 2012). Briefly, 15 ruminally and duodenally cannulated Holstein cows were randomly assigned to a treatment sequence in a crossover design experiment with a 14-d preliminary period and two 28-d treatment periods. Treatments were a Saccharomyces cerevisiae fermentation product (SCFP; Diamond V

Table 1. Primers used for quantitative real-time PCR detection of microbial species

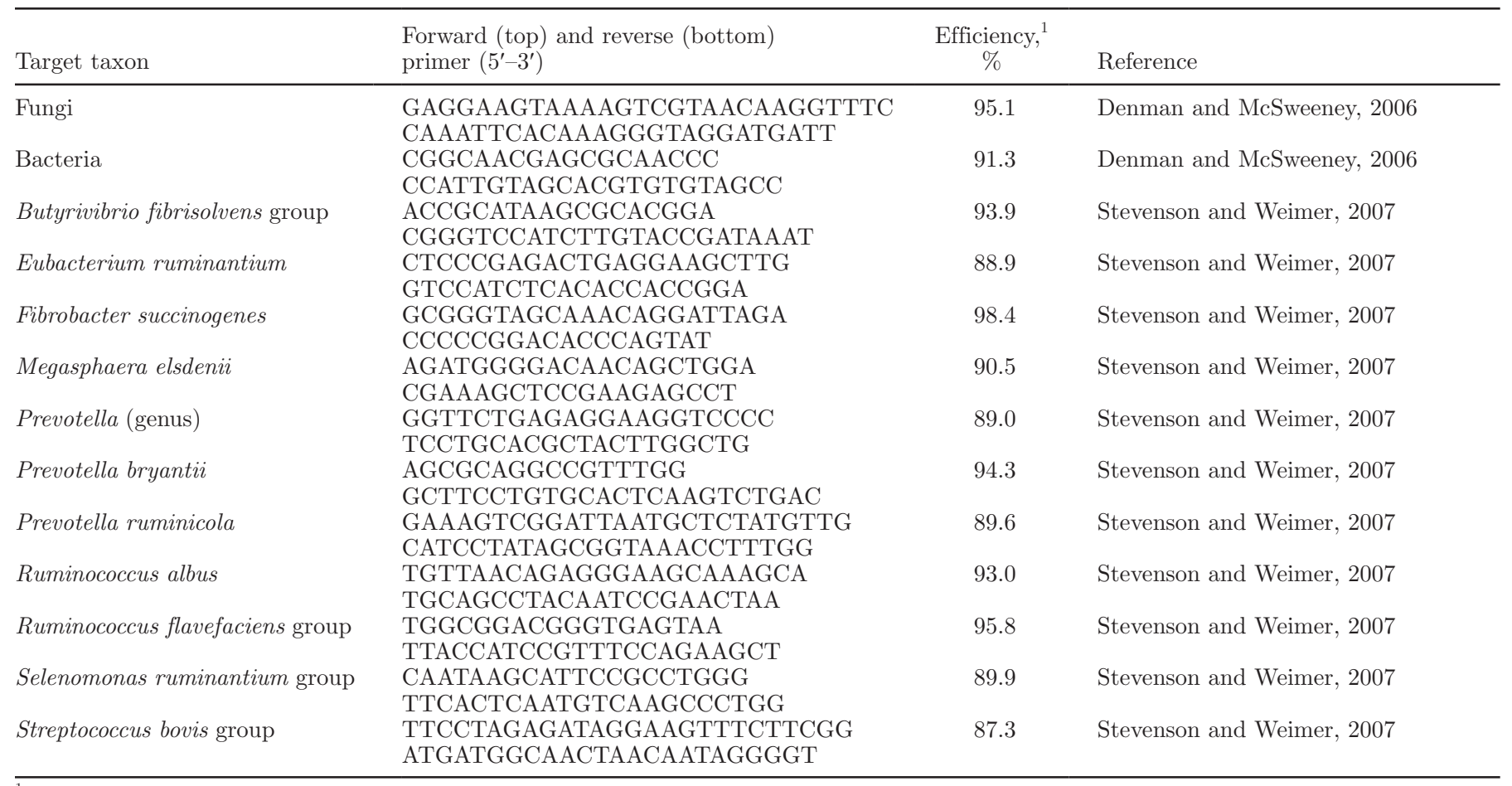

\footnotetext{
${ }^{1}$ Mean PCR efficiency determined using a 4-point sample dilution curve on each plate.
} 
XP Yeast Culture, Diamond V, Cedar Rapids, IA) and control (a mix of dry, finely ground shelled corn and soybean meal) top-dressed at a rate of $56 \mathrm{~g} / \mathrm{d}$. Cows with a wide range of DMI were selected for the experiment, and the preliminary period was used to establish basal cow characteristics for analysis of DMI interactions with treatment.

Rumen samples were collected during total rumen evacuations approximately $4 \mathrm{~h}$ after feeding on $\mathrm{d} 27$ and $42 \mathrm{~h}$ later at approximately $2 \mathrm{~h}$ before feeding on $\mathrm{d}$ 28 of each treatment period. Every tenth handful of rumen contents was collected during rumen evacuations, and the entire sample was separated into solid $(\mathrm{n}=60)$ and liquid $(\mathrm{n}=60)$ fractions, weighed, and samples were stored at $-20^{\circ} \mathrm{C}$. Total ruminal content mass, liquid and solid proportions, and DM content of each fraction were also determined (Allen and Ying, 2012). Solid and liquid fraction samples were lyophilized and ground. Samples (150 mg) were weighed into microcentrifuge tubes, and DNA was isolated as described for experiment 1.

Quantitative real-time PCR was performed in triplicate for each sample as described for experiment 1 with a few modifications. Each reaction included $2 \mu \mathrm{L}$ of DNA template in a $20-\mu \mathrm{L}$ volume, and all primers were included at $200 \mathrm{n} M$ concentrations. A normalized reporter value of 0.1 was used for all targets. In addition to the taxa investigated in experiment 1 , an additional 3 populations were quantified in experiment 2 (Table 1 ).

\section{Statistical Analysis}

The relative abundance of each microbial population was log-transformed and then statistically analyzed using a mixed model approach. The model for experiment 1 included the fixed effects of treatment and the random effects of cow and period, and contrast statements were used to assess the linear and quadratic responses to increasing inclusion rate of WCGF. Samples were deemed outliers and omitted from analysis when Studentized residuals were $>3$ or $<-3$; no more than 4 outliers were removed from any analysis. For experiment 2 , logtransformed means were averaged across sample times before the main analysis. The model for experiment 2 included fixed effects of period, rumen fraction, treatment, treatment $\times$ fraction, and treatment $\times$ period, as well as random effects of cow and period $\times$ cow. This model provided 13 denominator degrees of freedom for the treatment test.

Whole-rumen microbial population analysis was also carried out for experiment 2. Total bacterial concentrations in liquid and solid fraction samples were estimated as $2^{(-\mathrm{CT})}$ (Livak and Schmittgen, 2001). These relative bacterial populations were multiplied by the relative proportion of total rumen DM contents in solid and liquid fractions to determine the relative abundance of liquid versus solid-fraction bacteria. These scaling factors were then used to composite the population values mathematically for the 2 fractions analyzed at each time point into a single whole-rumen relative population $(\mathrm{n}=60)$. These values were log-transformed, averaged across sample times, and then analyzed using a model including fixed effects of period, treatment, and treatment $\times$ period, preliminary period DMI $(\mathbf{p D M I})$, $\mathrm{pDMI} \times$ treatment, $\mathrm{pDMI}^{2}$, and $\mathrm{pDMI}^{2} \times$ treatment as well as random effects of cow and period $\times$ cow. Covariate (pDMI) and interaction terms were removed from the model if $P>0.15$.

Finally, data from experiment 2 were also used to examine the explicit effect of sample time (within a day) on population estimates. For this analysis, logtransformed whole-rumen population data were analyzed using a model including fixed effects of period, treatment, treatment $\times$ period, rumen evacuation time, and rumen evacuation time $\times$ period, and the random effects of cow and period $\times$ cow.

For all analyses, reported means and SEM were backtransformed, significance was declared at $P \leq 0.05$, and tendencies were discussed at $0.05<P<0.10$.

\section{RESULTS AND DISCUSSION}

\section{Experiment 1}

Relative populations of the taxa investigated are presented in Table 2. The species considered have been well-described in previous studies (Hungate, 1966; Russell, 2002; Dehority, 2003). Although these organisms are commonly studied by rumen microbiologists and are of interest in rumen ecology, they accounted for an average of only $11.5 \%(6.82-15.7 \%)$ of the bacteria in the rumen in this experiment.

Dietary effects on production and ruminal fermentation have been reported in detail elsewhere (Mullins et al., 2010). As evidenced by changes in total VFA concentration, molar proportions of VFA, and ruminal $\mathrm{pH}$, fermentation was affected by inclusion of WCGF, indicating that ruminal microorganisms were somehow affected by dietary differences, although effects on absorption rate cannot be ruled out. In spite of this, treatments had no significant effects on the populations tested.

\section{Experiment 2}

Results of the initial analysis are shown in Table 3. Although several populations differed significantly be- 
Table 2. Effects of dietary wet corn gluten feed concentration on relative proportions of each taxon (\% of total bacteria) in ruminal contents ${ }^{1}$

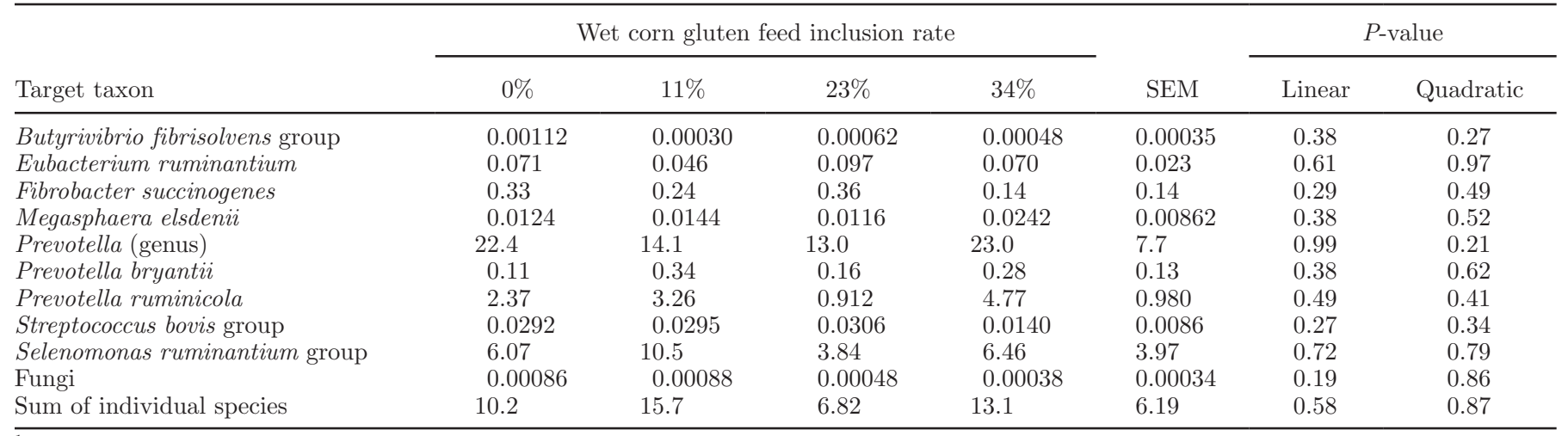

${ }^{1}$ Values are LSM; $\mathrm{n}=6$ to 7 .

tween liquid and solid fractions, we found no significant effects of treatment on the populations analyzed. Values were then weighted by the relative abundance of solid versus liquid fraction bacterial DNA and by the rumen pool of liquid versus solid fraction DM to determine the whole-rumen abundance of each population (Table 4). Analysis of these data failed to reveal any overall treatment effects. We observed a significant interaction between pDMI and SCFP for the ruminal digestion rate of starch in the rumen, where cows with normal pDMI (up to $26 \mathrm{~kg} / \mathrm{d}$ ) had higher rates of starch digestion when SCFP was supplemented, but high pDMI (greater than $26 \mathrm{~kg} / \mathrm{d}$ ) was associated with depressed rate of ruminal starch digestion with SCFP treatment (Allen and Ying, 2012). The current experiment was performed to determine if this observation was a result of shifts in the population in the rumen. Effects of pDMI and treatment interactions were significant only for the relative abundance of Eubacterium ruminantium, a hemicellulose fermenter (Figure 1). Animals with greater $\mathrm{pDMI}$ responded to SCFP with an increase in this population, but that was not the case for lowerintake cows. The response of E. ruminantium closely mirrors the response reported for ruminal OM digestibility in this study (Allen and Ying, 2012); however, the reason for the response of this species is unclear. No interaction between pDMI and SCFP was detected for ruminal $\mathrm{pH}$, suggesting that simple inhibition of $E$. ruminantium growth by an acidic environment cannot explain the response.

Ruminal samples were collected during total rumen evacuations at $1530 \mathrm{~h}$ ( $4 \mathrm{~h}$ after feeding) on d 27 and 42 $\mathrm{h}$ later at $0930 \mathrm{~h}$ ( $2 \mathrm{~h}$ before feeding) on d 28. An effect of sampling time was detected for total rumen bacteria, as well as fungi and some individual species (Figure 2). The total bacterial pool was significantly greater $(P=$ 0.001) after feeding compared with that before feeding, as was the total fungal population $(P=0.01)$. Bacterial populations normally increase after feeding (Bryant and Robinson, 1968), and it is not surprising that the

Table 3. Effects of dietary treatment on relative proportions (\% of total bacteria) of each population within solid and liquid fractions ${ }^{1}$

\begin{tabular}{|c|c|c|c|c|c|c|c|c|}
\hline \multirow[b]{2}{*}{ Target taxon } & \multicolumn{2}{|c|}{ Control } & \multicolumn{2}{|c|}{$\mathrm{SCFP}^{2}$} & \multirow[b]{2}{*}{ SEM } & \multicolumn{3}{|c|}{$P$-value } \\
\hline & Liquid & Solid & Liquid & Solid & & SCFP & Fraction & Interaction \\
\hline Butyrivibrio fibrisolvens group & 0.0301 & 0.0121 & 0.0243 & 0.0078 & 0.0077 & 0.28 & $<0.01$ & 0.72 \\
\hline Eubacterium ruminantium & 0.0646 & 0.1584 & 0.0675 & 0.2154 & 0.0396 & 0.31 & $<0.001$ & 0.59 \\
\hline Fibrobacter succinogenes & 0.166 & 0.402 & 0.324 & 0.528 & 0.125 & 0.11 & 0.01 & 0.42 \\
\hline Megasphaera elsdenii & 0.0272 & 0.0349 & 0.0273 & 0.0172 & 0.0136 & 0.42 & 0.69 & 0.18 \\
\hline Prevotella (genus) & 62.7 & 50.4 & 70.7 & 37.0 & 13.7 & 0.73 & 0.11 & 0.43 \\
\hline Prevotella bryantii & 0.311 & 0.339 & 0.406 & 0.188 & 0.109 & 0.57 & 0.26 & 0.16 \\
\hline Prevotella ruminicola & 1.803 & 0.874 & 2.330 & 0.521 & 0.476 & 0.71 & $<0.001$ & 0.19 \\
\hline Ruminococcus albus & 0.0362 & 0.0817 & 0.0469 & 0.0576 & 0.0169 & 0.89 & 0.04 & 0.21 \\
\hline Ruminococcus flavefaciens group & 2.207 & 2.752 & 3.029 & 2.455 & 0.565 & 0.67 & 0.97 & 0.27 \\
\hline Selenomonas ruminantium group & 1.365 & 1.036 & 1.765 & 1.087 & 0.296 & 0.54 & 0.07 & 0.62 \\
\hline Streptococcus bovis group & 0.0061 & 0.0015 & 0.0036 & 0.0012 & 0.0009 & 0.26 & $<0.001$ & 0.51 \\
\hline Fungi & 0.0078 & 0.0591 & 0.0109 & 0.0639 & 0.0244 & 0.52 & $<0.001$ & 0.68 \\
\hline Total bacteria, arbitrary units & 1.00 & 3.51 & 1.01 & 4.28 & 0.93 & 0.69 & $<0.001$ & 0.67 \\
\hline
\end{tabular}

${ }^{1}$ Values are LSM; $\mathrm{n}=15$ per fraction.

${ }^{2}$ Saccharomyces cerevisiae fermentation product. 
Table 4. Effects of treatment on weighted whole-rumen relative abundance of microbial species ${ }^{1}$

\begin{tabular}{lcccc}
\hline Target taxon, \% of total bacteria & Control & SCFP & SEM & $P$-value \\
\hline Butyrivibrio fibrisolvens group & 0.0154 & 0.0101 & 0.0049 & 0.37 \\
Eubacterium ruminantium & 0.153 & 0.208 & 0.033 & 0.21 \\
Fibrobacter succinogenes & 0.383 & 0.422 & 0.191 & 0.74 \\
Megasphaera elsdenii & 0.0365 & 0.0214 & 0.0153 & 0.18 \\
Prevotella (genus) & 53.4 & 42.8 & 8.5 & 0.24 \\
Prevotella bryantii & 0.367 & 0.324 & 0.087 & 0.60 \\
Prevotella ruminicola & 1.03 & 0.83 & 0.18 & 0.31 \\
Ruminococcus albus & 0.0801 & 0.0556 & 0.0191 & 0.19 \\
Ruminococcus flavefaciens group & 3.06 & 2.42 & 0.48 & 0.32 \\
Selenomonas ruminantium group & 0.978 & 0.974 & 0.286 & 0.99 \\
Streptococcus bovis group & 0.00212 & 0.00136 & 0.00042 & 0.18 \\
Fungi & 0.0550 & 0.0602 & 0.0425 & 0.82 \\
Total bacterial pool, arbitrary units & 1.00 & 1.28 & 0.41 & 0.25 \\
\hline
\end{tabular}

${ }^{1}$ Values are LSM; $\mathrm{n}=15$.

${ }^{2}$ Saccharomyces cerevisiae fermentation product.

microbial population decreased as available substrate diminished before the next feeding. In contrast, Li et al. (2009) did not observe any differences in the abundance of total bacteria (based on $16 \mathrm{~S}$ rRNA copies) when comparing samples collected $3 \mathrm{~h}$ before feeding, $3 \mathrm{~h}$ after feeding, or $9 \mathrm{~h}$ after feeding. The current results also demonstrated that some bacterial populations respond differently to time after feeding. Fibrobacter succinogenes was significantly more abundant $(P=0.03)$ after

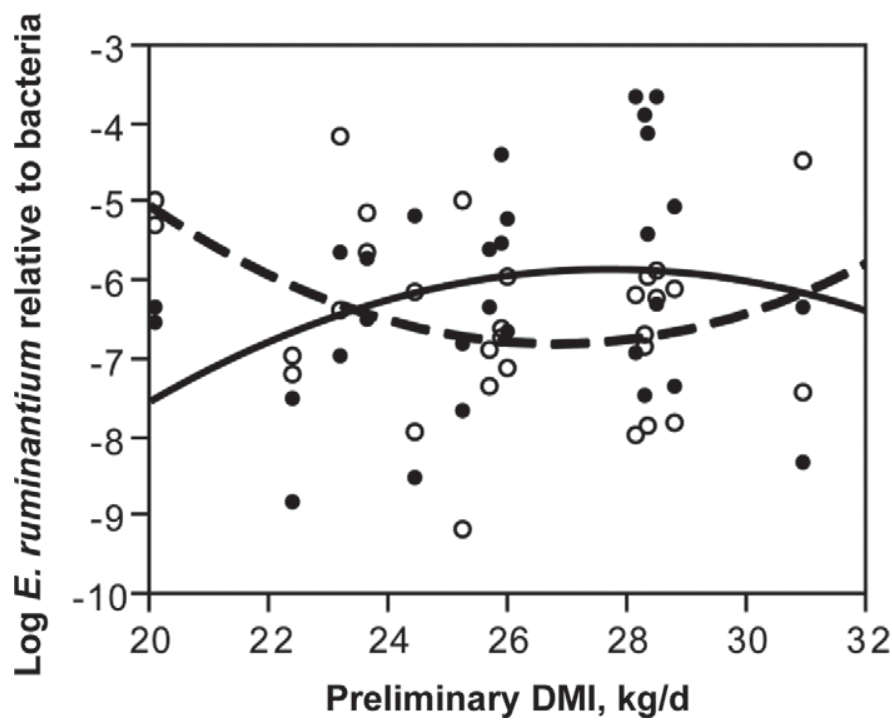

Figure 1. Saccharomyces cerevisiae fermentation product (SCFP) interacts with nutrient demand to influence Eubacterium ruminantium populations. Preliminary DMI shown on the x-axis represents the mean DMI of individual cows during the final $4 \mathrm{~d}$ of a preliminary period in which all cows were fed a common diet. The E. ruminantium population increased quadratically with increasing preliminary DMI for cows fed SCFP ( increasing preliminary DMI for controls $(O$, dashed line). Interaction of SCFP and quadratic effect of preliminary DMI: $P=0.06, \mathrm{n}=$ 30 per treatment. Points represent weighted whole-rumen populations from individual sample times (both a.m. and p.m.), but the statistical model accounted for subsampling within period. feeding than before feeding, whereas the population of Ruminococcus albus was lower $(P=0.05)$ after feeding. This is consistent with observations by Welkie et al. (2010), who observed changes in bacterial community composition as time after feeding increased.

\section{Ruminal Sampling}

Pioneers of the use of $\mathrm{qPCR}$ for analysis of ruminal microbe populations strained ruminal digesta to separate large particulate matter and then discarded the solids portion (Tajima et al., 2001; Klieve et al., 2003). That technique yields a clean, uniformly textured sample of rumen fluid for DNA extraction, but it eliminates the ability to account for microbes that remain attached to digesta particles. Stevenson and Weimer (2007) strained rumen fluid in a similar manner, but they retained the solids portion and processed it to obtain a microbial pellet. They then used $25 \mathrm{~mL}$ of ruminal fluid and $25 \mathrm{~g}$ of the microbial cell pellet for DNA extraction. This approach is effective but also labor intensive and requires rumen solids and fluid to be recombined for DNA isolation; therefore, unless one assumes a homogeneous distribution of cells, it is difficult to combine them in the exact ratio in which they are found in the rumen. Available evidence suggests that microorganisms attached to undigested feed particles comprise a major proportion of total ruminal microorganisms (Craig et al., 1987b), but many factors influence the proportion of particle-associated microbes (Merry and McAllan, 1983; Craig et al., 1987a). Therefore, the most accurate technique should be to obtain microbes adhering to feed particles and free-floating microbes in the same sample and then to extract DNA. The genetic material obtained in the procedure used in the current study is most likely representative of that combination. 

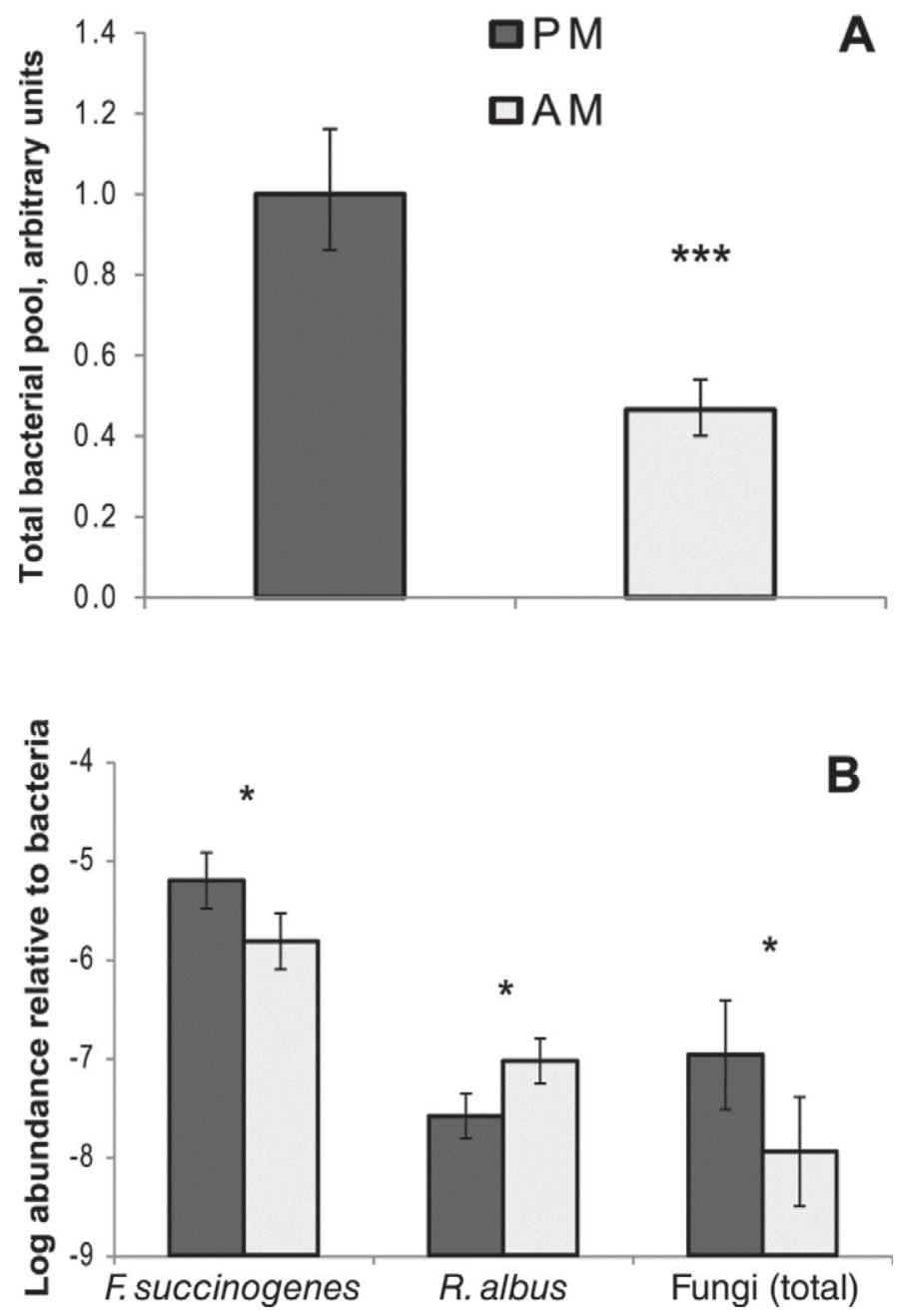

Figure 2. Ruminal populations vary by time of sampling. Ruminal samples collected $4 \mathrm{~h}$ after feeding (PM; $1530 \mathrm{~h}$, high rumen fill) and 2 $\mathrm{h}$ before feeding $42 \mathrm{~h}$ later (AM; $0930 \mathrm{~h}$, low rumen fill) were analyzed separately. (A) Total bacteria detected by quantitative real-time PCR were calculated based on bacterial abundance and total ruminal mass of solid and liquid fractions. Values are back-transformed LSM \pm SEM $(\mathrm{n}=30)$ expressed as arbitrary units with the p.m. mean set at 1.0 . ***The effect of time was significant $(P=0.001)$. (B) *Significant effects of sample time were detected for Fibrobacter succinogenes $(P=$ $0.03)$, Ruminococcus albus $(P=0.05)$, and total anaerobic fungi $(P=$ $0.01)$. Values are $\mathrm{LSM} \pm \mathrm{SEM}, \mathrm{n}=30$.

In experiment 2, we detected differences in the relative abundance of several species of bacteria between the solid and liquid fractions of rumen contents. In agreement with these species differences, several authors have reported differences in composition between solid-associated bacteria (SAB) and liquid-associated bacteria (LAB). For example, total-N content of rumen bacteria is often higher for samples isolated from the liquid fraction than for those isolated from the solid fraction of rumen contents (Merry and McAllan, 1983; Martin et al., 1994; Vincente et al., 2004), although variables such as diet (Cecava et al., 1990; González et al., 2012) and time of sampling relative to feeding (Craig et al., 1987a; Cecava et al., 1990) have been shown to affect this general pattern. Amino acid composition also has been shown to differ between these 2 populations (Martin et al., 1996).

We determined that an average of $92 \%$ of total bacterial DNA was found in the solid fraction. Previous authors have also noted that $\mathrm{SAB}$ make up a greater proportion of total rumen bacteria than LAB. Legay-Carmier and Bauchart (1989) estimated, by diaminopimelic acid (DAPA) content, that 67 and $73 \%$ of the total bacteria consisted of those adherent to particles for a soybean oil-supplemented and control diet, respectively. Craig et al. (1987b) determined that solid-associated microbial OM accounted for 70 to $80 \%$ of total microbial mass in the rumen. Martin and Michalet-Doreau (1995) found that SAB consisted of $74 \%$ of microbial mass by ${ }^{15} \mathrm{~N}$ labeling. Differences between studies are likely attributable to differences in techniques, time of sampling, animals, and diets. A key strength of the current study is that reported proportions are based on liquid and solid fractions recovered during total rumen evacuation, providing much greater accuracy than estimates derived from spot-sampling throughout the rumen. Although our estimate that $92 \%$ of bacterial DNA was in SAB is slightly higher than previous estimates, it is remarkable that diverse techniques quantifying nucleic acids, $\mathrm{OM}$, and $\mathrm{N}$ have found that $\mathrm{SAB}$ comprise $\geq 67 \%$ of total ruminal bacteria.

In combination with the differences between LAB and $\mathrm{SAB}$ discussed above, the high percentage of SAB found across studies is of particular concern considering that bacteria separated from the liquid fraction are often used as a marker of bacterial $\mathrm{N}$, whereas the bacteria in the solid fraction are often disregarded (Dewhurst et al., 2000). Diaminopimelic acid and purine content are frequently used as markers of bacterial protein synthesis and bacterial-N flow, and they have been shown to be different between SAB and LAB. In a review article, Clark et al. (1992) reported that LAB generally have higher purine: $\mathrm{N}$ and DAPA:N ratios compared with SAB, although some studies found no difference in purine: $\mathrm{N}$ between these fractions (Craig et al., 1987a; Firkins et al., 1987; Rodríguez-Prado et al., 2004). Because of the potential for elevated purine and DAPA concentration in bacteria associated with the fluid phase, experiments using LAB as a marker for bacterial protein may severely underestimate bacterial protein flow and synthesis. The observation that the vast majority of the bacteria may be located in the solid fraction opens the possibility for substantial bias if the $\mathrm{SAB}$ are overlooked when determining purine or DAPA concentrations as bacterial markers. 


\section{Population Responses to Dietary Changes}

The species (Table 1) monitored in this study are well characterized and are thought to be essential organisms in the rumen ecosystem, but they represent a minute proportion of all known ruminal microbes (Tajima et al., 1999; Kim et al., 2011). Our assumption in designing this experiment was that the selected species could serve as sentinels mirroring larger shifts in the ecosystem of the rumen. Observations from experiment 1 indicate that the 8 species quantified accounted for only 6 to $16 \%$ of all bacterial $16 \mathrm{~S}$ ribosomal DNA gene copies (Table 2). Similarly, in a meta-analysis of $16 \mathrm{~S}$ rRNA sequences, Kim et al. (2011) analyzed 13,478 bacterial sequences isolated from the rumen that defined 5,271 species-level operational taxonomic units. Of these sequences, only $6.5 \%$ were from cultured bacteria.

One weakness of qPCR analysis is the possibility that primers are nonspecific. Given the diversity of the rumen microbial ecosystem and the number of related species that can be present, it is difficult to conclusively demonstrate that primers are specific to a given species. Fortunately, independent analysis by metagenomic methods (which are not reliant on species-specific primers) have provided some external validation of primer design. Jami and Mizrahi (2012) compared abundance determined by qPCR and pyrosequencing for 5 populations, and found correlation coefficients $>0.88$ for all of them. This analysis included $F$. succinogenes and $M$. elsdenii, using the same primers used in the current study, providing direct validation of these 2 primer sets. This is in addition to the original validation provided by Denman and McSweeney (2006) and Stevenson and Weimer (2007).

In experiment 1, Prevotella ranged from 13 to $23 \%$ of total bacteria, whereas in experiment 2 , this genus ranged from 37.0 to $70.7 \%$ of bacteria within each fraction. Findings by previous authors quantifying Prevotella by qPCR have varied within and between studies, but have consistently found this genus to be highly abundant in the rumen. Wood et al. (1998) reported a combined relative abundance for both Prevotella and Bacteroides of $37 \%$ in a single cow rumen. Stiverson et al. (2011) observed a relative abundance of Prevotella from 27 to $61 \%$ of total bacteria. Stevenson and Weimer (2007) found that the Prevotella genus consisted of approximately half of the total bacteria (53 $\pm 8.1 \%$ ), ranging from 42 to $60 \%$ across the samples taken. The success of Prevotella in the rumen is likely related to the diversity of species and functions of this genus within the rumen ecosystem (Bekele et al., 2010).

The primary objective of this work was to use qPCR to quantify well-characterized bacteria in rumen samples from studies in which (1) a nonforage fiber source increased DMI and measures of ruminal fermentation (Mullins et al., 2010), and (2) SCFP supplementation influenced the rate of starch digestion in lactating cows, varying with level of feed intake (Allen and Ying, 2012). We hypothesized that the changes observed in these studies might have coincided with altered relative abundance of these organisms in the rumen; however, no effects of diet were observed on the microbial populations that were measured. Data shown in Tables 2 to 4 demonstrate that although variation between diets was observed, the standard errors of means were relatively high, indicating that the variation was not necessarily due to diet, but to other factors. It is important to recognize that SEM derived from the mixed model analyses used herein reflect not only residual variance but also inter-animal variation. Across the populations analyzed, individual animal accounted for as little as $10 \%$ and as much as $55 \%$ of the random variance in the model, suggesting that both unexplained variance (including technical imprecision) and variability between animals were important contributors to the variance observed here.

Alterations of the rumen bacterial profile are often difficult to maintain. Even attempts to manipulate the rumen microbiome directly have had unreliable results (Weimer, 1998); for example, when new organisms are introduced to the existing microbiome, as in the case of direct-fed microbials, results are inconsistent. Some have postulated that direct-fed microbials that colonize the rumen fill a specific niche unoccupied by the species already present in the rumen (Weimer, 1998). Ruminant nutritionists and microbiologists have largely worked on the assumption that the microbial population conforms to the substrate available for fermentation, and many studies have shown direct effects of dietary changes on the populations in the rumen (Kong et al., 2010; Pitta et al., 2010; Ramirez et al., 2012). Conversely, some studies, such as the current experiments, have not shown any effects, even while production responses were observed.

Brulc et al. (2009) observed markedly different populations even between animals consuming the same diet, indicating that other factors may have a stronger influence on the microbial population than dietary substrate. Some recent evidence indicates a degree of specificity of the microbiome to the ruminant animal itself (Weimer et al., 2010a), which may explain the rapid adaptation of the microbial population to dietary treatments. Animals fed the same diet and at similar levels of production may exhibit differences in their rumen microbial populations (Weimer et al., 2010b; Welkie et al., 2010). Mohammed et al. (2012) attempted to explain differences in severity of acidosis in the transition period through associated differences 
in the rumen bacterial community composition. The authors reported that bacterial community composition was not related to dietary treatment, and the shift in bacterial populations was greater for some individuals than for others, which also was not related to severity of acidosis. At the very least, such dramatic variation between individuals makes it difficult to demonstrate significant responses to subtle shifts in diets.

It is possible that the populations did shift in response to treatments imposed in these experiments, but migrated back to the original profile by the time of sampling. This could occur as a result of factors other than dietary substrate, such as specificity to the host animal. The treatment periods for both of the current experiments were 28 d. Weimer et al. (2010a) found that bacterial community composition had largely returned to its original state after the massive challenge of complete rumen contents exchange and had essentially completed this reversion by 9 wk postchallenge. Li et al. (2012) also showed that the bacterial population in the rumen returned to previous levels just $168 \mathrm{~h}$ after infusion of butyrate. Blanch et al. (2009) reported that microbial profiles returned to initial values $4 \mathrm{~d}$ after acidosis in beef heifers.

It is also possible that the key microbial adaptations in the ruminal ecosystems in these studies were at the level of microbe function rather than species composition. As high-throughput methods and microbial gene databases continue to develop, a meta-transcriptomics approach to such studies might be more fruitful. Some recent results have, in fact, suggested that despite large animal-to-animal variation in microbial communities, there is a likely a core set of genetic tools represented in the microbiome across animals (Jami and Mizrahi, 2012). Having the ability to assess the microbiome at the level of the functional enzymes (or the transcripts encoding them) presumably would allow for metabolic shifts to be observed as diets change, rather than the transient and highly variable species profiles.

\section{CONCLUSIONS}

The dietary treatments described in the current experiments affected the production and ruminal fermentation of the animals in the studies. In particular, we observed a significant interaction of pDMI and SCFP with the rate of ruminal starch digestion. We hypothesized that this was due to alterations in the microbial population in the rumen; however, no significant effect of treatment was observed on the populations analyzed, aside from changes in the relative abundance of $E$. ruminantium. Although the lack of significant dietary effects could be because the bacterial species analyzed account for less than $15 \%$ of the bacteria in the rumen, the results are consistent with recent reports that the bacterial community is highly specific to the ruminant host. Furthermore, it possible that microbial metabolism was altered rather than the populations themselves. Finally, the finding that approximately $90 \%$ of bacterial rRNA copies were associated with the solid phase of rumen contents has implications for markers of microbial protein flow from the rumen.

\section{ACKNOWLEDGMENTS}

The authors thank Cargill Inc. (Blair, NE) and Diamond V (Cedar Rapids, IA) for partial financial support of this research. This is contribution number 13-146-J from the Kansas Agricultural Experiment Station.

\section{REFERENCES}

Allen, M. S., and Y. Ying. 2012. Effects of Saccharomyces cerevisiae fermentation product on ruminal starch digestion are dependent upon dry matter intake for lactating cows. J. Dairy Sci. 95:65916605.

Bekele, A. Z., S. Koike, and Y. Kobayashi. 2010. Genetic diversity and diet specificity of ruminal Prevotella revealed by $16 \mathrm{~S}$ rRNA genebased analysis. FEMS Microbiol. Lett. 305:49-57.

Belanche, A., M. Doreau, J. E. Edwards, J. M. Moorby, E. Pinloche, and C. J. Newbold. 2012. Shifts in the rumen microbiota due to the type of carbohydrate and level of protein ingested by dairy cattle are associated with changes in rumen fermentation. J. Nutr. 142:1684-1692.

Blanch, M., S. Calsamiglia, N. DiLorenzo, A. DiCostanzo, S. Muetzel, and R. J. Wallace. 2009. Physiological changes in rumen fermentation during acidosis induction and its control using a multivalent polyclonal antibody preparation in heifers. J. Anim. Sci. 87:17221730 .

Brulc, J. M., D. A. Antonopoulos, M. E. Berg Miller, M. K. Wilson, A. C. Yannarell, E. A. Dinsdale, R. E. Edwards, E. D. Frank, J. B. Emerson, P. Wacklin, P. M. Coutinho, B. Henrissat, K. E. Nelson, and B. A. White. 2009. Gene-centric metagenomics of the fiber-adherent bovine rumen microbiome reveals forage specific glycoside hydrolases. Proc. Natl. Acad. Sci. USA 106:1948-1953.

Bryant, M. P., and I. M. Robinson. 1968. Effects of diet, time after feeding, and position sampled on numbers of viable bacteria in the bovine rumen. J. Dairy Sci. 51:1950-1955.

Cecava, M. J., N. R. Merchen, L. C. Gay, and L. L. Berger. 1990. Composition of ruminal bacteria harvested from steers as influenced by dietary energy level, feeding frequency, and isolation techniques. J. Dairy Sci. 73:2480-2488.

Clark, J. H., T. H. Klusmeyer, and M. R. Cameron. 1992. Microbial protein synthesis and flows of nitrogen fractions to the duodenum of dairy cows. J. Dairy Sci. 75:2304-2323.

Craig, W. M., G. A. Broderick, and D. B. Ricker. 1987b. Quantitation of microorganisms associated with the particulate phase of ruminal ingesta. J. Nutr. 117:56-62.

Craig, W. M., D. R. Brown, G. A. Broderick, and D. B. Ricker. 1987a. Post-prandial compositional changes of fluid- and particle-associated ruminal microorganisms. J. Anim. Sci. 65:1042-1048.

Dehority, B. A. 2003. Rumen Microbiology. Nottingham University Press, Nottingham, UK.

Denman, S. E., and C. S. McSweeney. 2006. Development of a realtime PCR assay for monitoring anaerobic fungal and cellulolytic bacterial populations within the rumen. FEMS Microbiol. Ecol. 58:572-582.

Dewhurst, R. J., D. R. Davies, and R. J. Merry. 2000. Microbial protein supply from the rumen. Anim. Feed Sci. Technol. 85:1-21. 
Firkins, J. L., L. L. Berger, N. R. Merchen, G. C. Fahey, and R. L. Mulvaney. 1987. Ruminal nitrogen metabolism in steers as affected by feed intake and dietary urea concentration. J. Dairy Sci. 70:2302-2311.

González, J., J. M. Arroyo, M. Ouarti, J. Guevara-Gonzalez, C. A. Rodriguez, M. R. Alvir, V. J. Moya, and O. Piquer. 2012. Composition of free and adherent ruminal bacteria: Inaccuracy of the microbial nutrient supply estimates obtained using free bacteria as reference samples and [15] $\mathrm{N}$ as the marker. Animal 6:468-475.

Hungate, R. E. 1966. The Rumen and Its Microbes. Academic Press, New York, NY.

Jami, E., and I. Mizrahi. 2012. Composition and similarity of bovine rumen microbiota across individual animals. PLoS ONE 7:e33306.

Khafipour, E., S. Li, J. C. Plaizier, and D. O. Krause. 2009. Rumen microbiome composition determined using two nutritional models of subacute ruminal acidosis. Appl. Environ. Microbiol. 75:7115-7124.

Kim, M., M. Morrison, and Z. Yu. 2011. Status of the phylogenetic diversity census of ruminal microbiomes. FEMS Microbiol. Ecol. $76: 49-63$.

Klieve, A. V., D. Hennessy, D. Ouwerkerk, R. J. Forster, R. I. Mackie, and G. T. Attwood. 2003. Establishing populations of Megasphaera elsdenii YE 34 and Butyrivibrio fibrisolvens YE 44 in the rumen of cattle fed high grain diets. J. Appl. Microbiol. 95:621-630.

Kong, Y., R. Teather, and R. Forster. 2010. Composition, spatial distribution, and diversity of bacterial communities in the rumen of cows fed different forages. FEMS Microbiol. Ecol. 74:612-622.

Legay-Carmier, F., and D. Bauchart. 1989. Distribution of bacteria in the rumen contents of dairy cows given a diet supplemented with soyabean oil. Br. J. Nutr. 61:725-740.

Li, M., G. B. Penner, E. Hernandez-Sanabria, M. Oba, and L. L. Guan. 2009. Effects of sampling location and time, and host animal on assessment of bacterial diversity and fermentation parameters in the bovine rumen. J. Appl. Microbiol. 107:1924-1934.

Li, R. W., S. Wu, R. L. V. I. Baldwin, W. Li, and C. Li. 2012. Perturbation dynamics of the rumen microbiota in response to exogenous butyrate. PLoS ONE 7:e29392.

Livak, K. J., and T. D. Schmittgen. 2001. Analysis of relative gene expression data using quantitative real-time PCR and the $2^{-\Delta \Delta \mathrm{C}(\mathrm{T})}$ method. Methods 25:402-408.

Martin, C., L. Bernard, and B. Michalet-Doreau. 1996. Influence of sampling time and diet on amino acid composition of protozoal and bacterial fractions from bovine ruminal contents. J. Anim. Sci. 74:1157-1163.

Martin, C., and B. Michalet-Doreau. 1995. Variations in mass and enzyme activity of rumen microorganisms: Effect of barley and buffer supplements. J. Sci. Food Agric. 67:407-413.

Martin, C., A. G. Williams, and B. Michalet-Doreau. 1994. Isolation and characteristics of the protozoal and bacterial fractions from bovine ruminal contents. J. Anim. Sci. 72:2962-2968.

Merry, R. J., and A. B. McAllan. 1983. A comparison of the chemical composition of mixed bacteria harvested from the liquid and solid fractions of rumen digesta. Br. J. Nutr. 50:701-709.

Mohammed, R., D. M. Stevenson, P. J. Weimer, G. B. Penner, and K. A. Beauchemin. 2012. Individual animal variability in ruminal bacterial communities and ruminal acidosis in primiparous Holstein cows during the periparturient period. J. Dairy Sci. 95:6716-6730.

Mullins, C. R., K. N. Grigsby, D. E. Anderson, E. C. Titgemeyer, and B. J. Bradford. 2010. Effects of feeding increasing levels of wet corn gluten feed on production and ruminal fermentation in lactating dairy cows. J. Dairy Sci. 93:5329-5337.

Pitta, D. W., W. E. Pinchak, S. E. Dowd, J. Osterstock, V. Gontcharova, E. Youn, K. Dorton, I. Yoon, B. R. Min, J. D. Fulford, T. A. Wickersham, and D. P. Malinowski. 2010. Rumen bacterial diversity dynamics associated with changing from Bermudagrass hay to grazed winter diets. Microb. Ecol. 59:511-522.

Ramirez, H. A. R., K. Nestor, L. O. Tedeschi, T. R. Callaway, S. E. Dowd, S. C. Fernando, and P. J. Kononoff. 2012. The effect of brown midrib corn silage and dried distillers' grains with solubles on milk production, nitrogen utilization and microbial community structure in dairy cows. Can. J. Anim. Sci. 92:365-380.

Rodríguez-Prado, M., S. Calsamiglia, and A. Ferret. 2004. Effects of fiber content and particle size of forage on the flow of microbial amino acids from continuous culture fermenters. J. Dairy Sci. $87: 1413-1424$

Russell, J. B. 2002. Rumen Microbiology and its Role in Ruminant Nutrition. J. B. Russell, Ithaca, NY.

Stevenson, D. M., and P. Weimer. 2007. Dominance of Prevotella and low abundance of classical ruminal bacterial species in the bovine rumen revealed by relative quantification real-time PCR. Appl. Microbiol. Biotechnol. 75:165-174.

Stiverson, J., M. Morrison, and Z. Yu. 2011. Populations of select cultured and uncultured bacteria in the rumen of sheep and the effect of diets and ruminal fractions. Int. J. Microbiol. 2011:750613.

Tajima, K., R. I. Aminov, T. Nagamine, H. Matsui, M. Nakamura, and Y. Benno. 2001. Diet-dependent shifts in the bacterial population of the rumen revealed with real-time PCR. Appl. Environ. Microbiol. 67:2766-2774.

Vincente, F., J. A. Guada, J. Surra, J. Balcells, and C. Castrillo. 2004. Microbial contribution to duodenal purine flow in fattening cattle given concentrate diets, estimated by purine $\mathrm{N}$ labeling $([15] \mathrm{N})$ of different microbial fractions. Anim. Sci. 78:159-167.

Weimer, P. J. 1998. Manipulating ruminal fermentation: A microbial ecological perspective. J. Anim. Sci. 76:3114-3122.

Weimer, P. J., D. M. Stevenson, H. C. Mantovani, and S. L. C. Man. 2010a. Host specificity of the ruminal bacterial community in the dairy cow following near-total exchange of ruminal contents. J. Dairy Sci. 93:5902-5912.

Weimer, P. J., D. M. Stevenson, and D. R. Mertens. 2010b. Shifts in bacterial community composition in the rumen of lactating dairy cows under milk fat-depressing conditions. J. Dairy Sci. 93:265278

Weimer, P. J., G. C. Waghorn, C. L. Odt, and D. R. Mertens. 1999. Effect of diet on populations of three species of ruminal cellulolytic bacteria in lactating dairy cows. J. Dairy Sci. 82:122-134.

Welkie, D. G., D. M. Stevenson, and P. J. Weimer. 2010. ARISA analysis of ruminal bacterial community dynamics in lactating dairy cows during the feeding cycle. Anaerobe 16:94-100.

Wood, J., K. P. Scott, G. Avguštin, C. J. Newbold, and H. J. Flint. 1998. Estimation of the relative abundance of different Bacteroides and Prevotella ribotypes in gut samples by restriction enzyme Profiling of PCR-amplified 16S rRNA gene sequences. Appl. Environ. Microbiol. 64:3683-3689.

Yu, Z., and M. Morrison. 2004. Improved extraction of PCR-quality community DNA from digesta and fecal samples. Biotechniques $36: 808-812$. 